\title{
The future in Rhinology: from local treatment, to monoclonals and influencing the microbiome
}

Over the last few decades, rhinology has been one of the most dynamic and progressive areas of ENT. We have not experienced such an intense period of development since the introduction of nasal corticosteroids in the 1970s.

In this issue of our Journal, we report on the first Rhinology Future Debate organized by EUFOREA (European Forum for Research and Education in Allergy and Airways diseases) ${ }^{(1)}$. For the first time in Rhinology, a peer to peer scientific exchange with key experts in the field of rhinology and key medical colleagues from leading industries let to a brainstorming and discussion event on a number of hot issues in Rhinology. Apart from this report in Rhinology, all the debates were recorded and distributed on-line (www.rhinology-future.com). The debate touched upon a number of hot issues like the improvements in local treatment in chronic rhinosinusitis (CRS), the development of biologicals for chronic rhinosinusitis with nasal polyps (CRSwNP), the role of balloons in sinus surgery in Europe, and the place of navigation in daily practice. In this way, EUFOREA aims at maximizing the education of the target groups on novel developments, allowing a critical appraisal of the future and a more rapid implementation of promising novel tools, techniques and/or molecules in clinical practise in Europe. These new developments and optimal information of practitioners and patients alike, combined with a precision approach to the patients and the disease ${ }^{(2)}$, will significantly change our daily practice. In the near future, we can expect most of our patients to be treated effectively with high dose local corticosteroids ${ }^{(3-5)}$, and if that is insufficient, with monoclonal antibodies ${ }^{(6,7)}$. Surgery will only be needed for a limited group of patients. The decision to operate (again) can be difficult for patients and otorhinolaryngologists alike. CRS is a chronic inflammatory disease that usually cannot be solved by surgery alone. We explain our patients that the primary goal of the surgery is to open the sinuses and improve the access for local treatment and that nasal irrigations ${ }^{(8)}$ and anti-inflammatory treatment after surgery is mandatory (9). Although we know certain symptoms, like smell ${ }^{(10)}$ and postnasal drip are more difficult to treat than others like blockage ${ }^{(11)}$ and sleep impairment ${ }^{(12,13)}$, in recent years a number of studies have evaluated appropriate indications for endoscopic sinus surgery (ESS) for chronic rhinosinusitis (CRS) ${ }^{(14-16)}$. Interestingly and contrary to earlier findings ${ }^{(17)}$ socioeconomic differences do not seem to have an influence on the prevalence of CRS (18). Apart from the EUFOREA report, we have a lot of very interesting papers on diverse subjects from allergic rhinitis ${ }^{(19,20)}$, via risk factors for epistaxis ${ }^{(21)}$, to surgical papers on inverted papilloma ${ }^{(22)}$ and CSF leak repair ${ }^{(23)}$.

In this issue of the journal, the group of Sarah Vreugde en PJ Wormald describe that $S$. aureus is found intracellularly within CRSwNP tissue of patients with recalcitrant disease at multiple time points without an increase in inflammatory response supporting their hypothesis that $S$. aureus is able to escape from host detection and resides within the sinonasal mucosa despite intense treatment ${ }^{(24)}$. This might be an explanation why the effect of antibiotics, even given long-term in CRS are limited ${ }^{(25-27)}$. But maybe the idea that one unique microbe can be the cause of CRS is too simplistic. In recent years the cultivation-independent, molecular methods and the bioinformatics tools used to analyse sequence data, have offered us unprecedented insights into potential microbial involvement in CRS. We learned that our sinuses are not sterile as was thought for decades. Since the first paper from the group of Susan Lynch ${ }^{(28)}$ pointing at the dysbiosis in CRS with overrepresentation of Corynebacterium tuberculostearicum suggesting both a new sino-pathogen and a strong bacterial candidate for therapeutic intervention, a significant number of papers have been published ${ }^{(29-31)}$. A systematic review of the sinonasal microbiome in chronic rhinosinusitis published last year was a little disheartening in its conclusion: although there are common phyla present in both control patients and patients with CRS, no consistent enrichment of any particular taxon was identified ${ }^{(30)}$.

The group of Richard Douglas explains the technical details of the bioinformatic approach to microbiome research beyond description of diversity ${ }^{(32)}$. They used these techniques to reanalyse available sinonasal genomic data and observed that an increased relative abundance of the members belonging to the phylum Actinobacteria and members from the genera Propionibacterium appeared to differentiate healthy sinuses from those that were chronically inflamed. Furthermore, they observed that an absence of Burkholderia and Propionibacterium phylotypes from the healthy community dataset was correlated with a significant increase in network fragmentation, suggesting a "gate-keeper" role of these phyla in sinonasal microbiota homeostasis ${ }^{(31)}$. Coming back to the use of antibiotics: maybe they do more bad than good: removal of keystone or gatekeeper bacterial species, an increase in antibiotic resistance, and loss of diversity which can contribute to disease predisposition and perpetuation of an aberrant bacterial community structure (32). 
1. Fokkens WJ, Bachert C, Bernal-Sprekelsen M et al. EUFOREA, Rhinology Future Debates Report*. Rhinology. 2017;55(4):298-304.

2. Muraro A, Fokkens WJ, Pietikainen S, et al. European symposium on precision medicine in allergy and airways diseases: report of the European Union parliament symposium. Rhinology. 2015;53(4):303-7.

3. Forwith KD, Han JK, Stolovitzky JP, et al RESOLVE: bioabsorbable steroid-eluting sinus implants for in-office treatment of recurrent sinonasal polyposis after sinus surgery: 6-month outcomes from a randomized, controlled, blinded study. Int Forum Allergy Rhinol. 2016 Jun;6(6):573-81.

4. Adriaensen G, Lim KH, Fokkens WJ. Safety and efficacy of a bioabsorbable fluticasone propionate-eluting sinus dressing in postoperative management of endoscopic sinus surgery: a randomized clinical trial. Int Forum Allergy Rhinol. 2017 Aug;7(8):813820.

5. Han JK, Forwith KD, Smith TL, Kern RC, Brown WJ, Miller SK, et al. RESOLVE: a randomized, controlled, blinded study of bioabsorbable steroid-eluting sinus implants for in-office treatment of recurrent sinonasal polyposis. Int Forum Allergy Rhinol. 2014 Nov;4(11):861-70

6. Bachert C, Mannent L, Naclerio RM, et al. Effect of Subcutaneous Dupilumab on Nasal Polyp Burden in Patients With Chronic Sinusitis and Nasal Polyposis: A Randomized Clinical Trial. JAMA. 2016;315:469-79.

7. Bachert C, Sousa AR, Lund VJ, et al. Reduced need for surgery in severe nasal polyposis with mepolizumab: Randomized trial. The Journal of allergy and clinical immunology. 2017.

8. Giotakis Al, Karow EM, Scheithauer MO, Weber R, Riechelmann H. Saline irrigations following sinus surgery - a controlled, single blinded, randomized trial. Rhinology. 2016;54(4):302-10.

9. Pundir V, Pundir J, Lancaster $G$, et al. Role of corticosteroids in Functional Endoscopic Sinus Surgery - a systematic review and meta-analysis. Rhinology. 2016;54(1):3-19.

10. Vandenhende-Szymanski C, Hochet B, Chevalier D, Mortuaire G. Olfactory cleft opacity and CT score are predictive factors of smell recovery after surgery in nasal polyposis. Rhinology. 2015;53(1):29-34.

11. Sahlstrand-Johnson P, Hopkins C, Ohlsson $B$, Ahlner-Elmqvist $M$. The effect of endoscopic sinus surgery on quality of life and absenteeism in patients with chronic rhinosinuitis - a multi-centre study. Rhinology. 2017;55(3):251-61.
12. Varendh $M$, Johannisson $A$, Hrubros-Strom $H$, Andersson M. Sleep quality improves with endoscopic sinus surgery in patients with chronic rhinosinusitis and nasal polyposis. Rhinology. 2017 Mar 1;55(1):45-52.

13. Hopkins C, Philpott C, Crowe S, et al Identifying the most important outcomes for systematic reviews of interventions for rhinosinusitis in adults: working with Patients, Public and Practitioners. Rhinology. 2016;54(1):20-6

14. Leung RM, Dinnie K, Smith TL. When do the risks of repeated courses of corticosteroids exceed the risks of surgery? Int Forum Allergy Rhinol. 2014 Nov;4(11):871-6

15. Rudmik L, Soler ZM, Hopkins C, et al. Defining appropriateness criteria for endoscopic sinus surgery during management of uncomplicated adult chronic rhinosinusitis: a RAND/UCLA appropriateness study. Rhinology. 2016;54(2):117-28.

16. Rudmik L, Soler ZM, Hopkins C. Using postoperative SNOT-22 to help predict the probability of revision sinus surgery. Rhinology. 2016;54(2):111-6.

17. Kilty SJ, McDonald JT, Johnson S, Al-Mutair D. Socioeconomic status: a disease modifier of chronic rhinosinusitis? Rhinology. 2011:49(5):533-7.

18. Philpott C, Erskine S, Hopkins C, et al. A case-control study of medical, psychological and socio-economic factors influencing the severity of chronic rhinosinusitis. Rhinology. 2016;54(2):134-40.

19. Izquierdo-Dominguez A, Jauregui I, Del Cuvillo A, et al. Allergy rhinitis: similarities and differences between children and adults. Rhinology. 2017;55:326-331.

20. Lin L, Dai F, Wei JJ, Tang XY, Chen Z, Sun GB. Allergic inflammation is exacerbated by allergen-induced type 2 innate lymphoid cells in a murine model of allergic rhinitis. Rhinology. 2017; 55:339-347.

21. Seidel DU, Jacob L, Kostev K, Sesterhenn AM. Risk factors for epistaxis in patients followed in general practices in Germany. Rhinology. 2017:55:312-318.

22. Bertazzoni G, Accorona R, Schreiber A, Pietrobon G, Karligkiotis A, Fazio E, et al. Postoperative long-term morbidity of extended endoscopic maxillectomy for inverted papilloma. Rhinology. 2017:55:319325.

23. Workman AD, Carey RM, Parasher AK, Kuan EC, Godovchik J, Glicksman JT, et al. The fate of the bone graft in cerebrospinal fluid rhinorrhea endoscopic repair for idiopathic intracranial hypertension: a retrospective case series analysis. Rhinology. 2017;55:376-
381

24. Ou J, Bassiouni A, Drilling A, Psaltis AJ, Vreugde S, Wormald PJ. The persistence of intracellular Staphylococcus aureus in the sinuses: a longitudinal study. Rhinology. 2017; 55:305-311.

25. Pinto Bezerra Soter AC, Bezerra TF, Pezato $\mathrm{R}$, et al. Prospective open-label evaluation of long-term low-dose doxycycline for difficult-to-treat chronic rhinosinusitis with nasal polyps. Rhinology. 2017;55(2):175-80

26. De Schryver E, Derycke L, Calus L, et al. The effect of systemic treatments on periostin expression reflects their interference with the eosinophilic inflammation in chronic rhinosinusitis with nasal polyps. Rhinology. 2017:55(2):152-60.

27. Videler WJ, Badia L, Harvey RJ, et al. Lack of efficacy of long-term, low-dose azithromycin in chronic rhinosinusitis: a randomized controlled trial. Allergy. 2011 Nov;66(11):1457-68

28. Abreu NA, Nagalingam NA, Song $Y$, et al. Sinus microbiome diversity depletion and Corynebacterium tuberculostearicum enrichment mediates rhinosinusitis. Science translational medicine. 2012:4(151):151 ra24.

29. Ivanchenko OA, Karpishchenko SA, Kozlov $\mathrm{RS}$, et al. The microbiome of the maxillary sinus and middle nasal meatus in chronic rhinosinusitis. Rhinology. 2016;54(1):68-74.

30. Anderson M, Stokken J, Sanford T, Aurora $R$, Sindwani R. A systematic review of the sinonasal microbiome in chronic rhinosinusitis. Am J Rhinol Allergy. 2016 May;30(3):161-6.

31. Wagner Mackenzie B, Waite DW, Hoggard M, Douglas RG, Taylor MW, Biswas K. Bacterial community collapse: a meta-analysis of the sinonasal microbiota in chronic rhinosinusitis. Environ Microbiol. 2017 Jan;19(1):381-392.

32. Wagner Mackenzie B, Waite DW, Hoggard M, Taylor MW, Biswas K, Douglas RG. Moving beyond descriptions of diversity: clinical and research implications of bacterial imbalance in chronic rhinosinusitis. Rhinology. 2017:55:291-297.

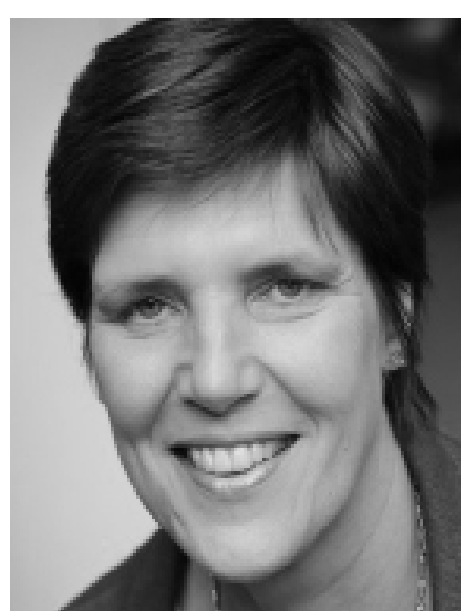

